\title{
Comorbidity as a contributor to frequent severe acute exacerbation in COPD patients
}

\author{
This article was published in the following Dove Press journal: \\ International Journal of COPD \\ 4 August 2016 \\ Number of times this article has been viewed
}

\author{
Suk Hyeon Jeong ${ }^{1, *}$ \\ Hyun Lee ${ }^{1, *}$ \\ KC Carriere ${ }^{2,3}$ \\ Sun Hye Shin' \\ Seong Mi Moon' \\ Byeong-Ho Jeong' \\ Won-Jung Koh' \\ Hye Yun Park'
}

'Division of Pulmonary and Critical Care Medicine, Department of Medicine, Samsung Medical Center, Sungkyunkwan University School of Medicine, Seoul, South Korea;

${ }^{2}$ Department of Mathematical and Statistical Sciences, University of Alberta, Edmonton, Alberta, Canada; ${ }^{3}$ Biostatistics and Clinical Epidemiology Center, Samsung Medical Center, Seoul, South Korea

*These authors contributed equally to this work
Correspondence: Hye Yun Park Division of Pulmonary and Critical Care Medicine, Department of Medicine, Samsung Medical Center, Sungkyunkwan University School of Medicine, 8I Irwon-ro, Gangnam-gu, Seoul 0635I, South Korea

$\mathrm{Tel}+82234103429$

Fax +82 234103849

Email hyeyunpark@skku.edu
Background: Comorbidities have a serious impact on the frequent severe acute exacerbations (AEs) in patients with COPD. Previous studies have used the Charlson comorbidity index to represent a conglomerate of comorbidities; however, the respective contribution of each coexisting disease to the frequent severe AEs remains unclear.

Methods: A retrospective, observational study was performed in 77 COPD patients who experienced severe AE between January 2012 and December 2014 and had at least 1-year follow-up period from the date of admission for severe AE. We explored the incidence of frequent severe AEs ( $\geq 2$ severe AEs during 1-year period) in these patients and investigated COPD-related factors and comorbidities as potential risk factors of these exacerbations.

Results: Out of 77 patients, 61 patients $(79.2 \%)$ had at least one comorbidity. During a 1-year follow-up period, 29 patients (37.7\%) experienced frequent severe AEs, approximately two-thirds $(n=19)$ of which occurred within the first 90 days after admission. Compared with patients not experiencing frequent severe AEs, these patients were more likely to have poor lung function and receive home oxygen therapy and long-term oral steroids. In multiple logistic regression analysis, coexisting asthma (adjusted odds ratio $[\mathrm{OR}]=4.02,95 \%$ confidence interval $[\mathrm{CI}]=1.30-12.46, P=0.016)$, home oxygen therapy $($ adjusted $\mathrm{OR}=9.39,95 \%$ $\mathrm{CI}=1.60-55.30, P=0.013$ ), and $\mathrm{C}$-reactive protein (adjusted $\mathrm{OR}=1.09,95 \% \mathrm{CI}=1.01-1.19$, $P=0.036)$ were associated with frequent severe AEs. In addition, poor lung function, as measured by forced expiratory volume in 1 second (adjusted OR $=0.16,95 \% \mathrm{CI}=0.04-0.70$, $P=0.015$ ), was inversely associated with early (ie, within 90 days of admission) frequent severe AEs.

Conclusion: Based on our study, among COPD-related comorbidities, coexisting asthma has a significant impact on the frequent severe AEs in COPD patients.

Keywords: asthma, chronic obstructive pulmonary disease, comorbidity, exacerbation

\section{Introduction}

Acute exacerbations (AEs) of chronic obstructive pulmonary disease (COPD) are defined as an acute worsening of symptoms beyond normal day-to-day variations ${ }^{1}$ and are a key determinant of the natural course of COPD. Frequent exacerbations are associated with more rapid decline in lung function, ${ }^{2,3}$ poor quality of life, ${ }^{4,5}$ considerable morbidity and mortality, ${ }^{6-11}$ and high socioeconomic costs. ${ }^{12}$ Moreover, it has been shown that severe exacerbation episodes, that is, those requiring an emergency department visit or hospitalization, have a deleterious effect on COPD prognosis, especially when these events occur frequently. ${ }^{2,9}$

COPD often coexists with other diseases that can significantly impact the prognosis of patients with COPD. Previous studies showed that severe AE is associated with a higher prevalence of comorbidities and increased hospital readmission rate, ${ }^{10}$ 
and demonstrated that better management of these comorbidities contributed to an improved COPD prognosis after hospital discharge. ${ }^{11}$ However, since these studies used the Charlson comorbidity index ${ }^{13}$ as a single compound variable for the assessment of comorbidities ${ }^{10,11,14}$ or classified patients into two groups (with and without comorbidities) without further subdivision, ${ }^{15,16}$ the respective contribution of each comorbid condition on the development of severe AEs remains unclear. In addition, extrapulmonary diseases such as hypertension, ischemic heart disease (IHD), depression, and diabetes mellitus were investigated, whereas coexisting pulmonary diseases, such as asthma and tuberculosis-destroyed lung (TDL), were rarely considered as comorbidities. ${ }^{6-11}$ Therefore, we investigated factors associated with frequent severe AEs in COPD patients based on COPD-related factors and comorbidities, including coexisting pulmonary diseases.

\section{Methods}

\section{Study population}

A retrospective observational study was carried out in Samsung Medical Center, a 1,961-bed referral hospital in Seoul, South Korea. The medical records of 128 patients with COPD who visited the emergency department or were admitted to our hospital for the management of COPD AE between January 2012 and December 2014 and had at least 1-year follow-up after severe AE were reviewed. Exclusion criteria included patients who were lost to follow-up $(n=33)$, as well as those who were transferred to other hospitals $(n=5)$, or died either during the index admission $(n=4)$ or of other unknown causes $(n=9)$ during the follow-up period. A total of 77 patients were included in the present study. This study was approved by the Institutional Review Board of Samsung Medical Center, and the informed consent requirement was waived due to the retrospective nature of this study. All patient information was anonymized and de-identified before analysis.

\section{Definitions}

The severe COPD AE was defined as a COPD-associated event requiring either an emergency department visit or hospitalization and treatment with systemic steroids and/or antibiotics. ${ }^{17}$ Frequent severe AEs were defined as two or more severe COPD AEs occurring within 1 year, ${ }^{18}$ while early frequent severe AEs was used to describe the occurrence of two or more severe AEs within 3 months. The severity of airflow limitation was defined as follows: mild (forced expiratory volume in 1 second $\left[\mathrm{FEV}_{1}\right] \geq 80 \%$ of the predicted value), moderate $\left(50 \% \leq \mathrm{FEV}_{1}<80 \%\right.$ of the predicted value), severe $\left(30 \% \leq \mathrm{FEV}_{1}<50 \%\right.$ of the predicted value), and very severe $\left(\mathrm{FEV}_{1}<30 \%\right.$ of the predicted value).

The following comorbidities were evaluated in this study: hypertension, IHD (ie, stable angina, unstable angina, and myocardial infarction), congestive heart failure, cerebrovascular disease, cor pulmonale, diabetes mellitus, malignancy, asthma, TDL, chronic liver disease, and chronic kidney disease. Patients with one or more of these comorbidities as diagnosed by a physician or on medication for these conditions were evaluated according to their respective comorbidities. Patients with congestive heart failure were defined as those with symptoms suggestive of heart failure and an ejection fraction $<40 \%$ on echocardiography. ${ }^{19}$ Patients with TDL were required to have both insufficient lung function and parenchymal lung damage, both of which had to have been caused by previous tuberculosis infection. ${ }^{20}$ A COPD patient with prior echocardiography findings consistent with an estimate of peak systolic pulmonary pressure $>30 \mathrm{mmHg}$ was regarded as having cor pulmonale. ${ }^{21}$ The COPD-related clinical factors included the following variables: body mass index (BMI), smoking history, pulmonary function, COPDrelated medications, the long-term use of systemic steroids at a dose $\geq 5 \mathrm{mg}$ prednisolone for $>3$ months, and home oxygen therapy.

\section{Data collection}

Data were retrospectively collected through a comprehensive review of each patient's medical chart, medications, and imaging studies. Clinical factors were obtained during the index admission, including age, sex, smoking history, BMI, comorbidities (hypertension, IHD, congestive heart failure, cerebrovascular disease, cor pulmonale, diabetes mellitus, malignancy, asthma, TDL, chronic liver disease, and chronic kidney disease), $\mathrm{FEV}_{1}$, C-reactive protein (CRP), home oxygen therapy, inhaled treatments, and long-term oral steroid use. Pulmonary function test data conducted within 1 year prior to or after severe AE episode were retrieved, except one patient who performed pulmonary function test 3 years prior to severe AE. Following the index severe AE episode, the medical records were reviewed to collect data on the recurrence of severe AEs within 90 days and 1 year of the index hospitalization.

\section{Statistical analysis}

Data were presented as numbers $(\%)$ for categorical variables and as median and interquartile range values (IQR, Q1-Q3) 
for continuous variables. Categorical variables were compared with either the Pearson $\chi^{2}$ test or Fisher's exact test, and continuous variables were compared using MannWhitney $U$-test due to skewed data. To explore the clinical factors that were independently associated with frequent severe AEs within the 90-day and 1-year follow-up periods, we fitted a multiple logistic regression analysis with the stepwise selection method. We used a backward elimination with the removal criteria of $P<0.1$ to calculate the odds ratios (OR) for recurrence of severe AEs during the follow-up period. Age, sex, and factors with $P<0.20$ in univariate analyses, and clinical relevant (coexisting asthma, IHD, and congestive heart failure) were entered into the multiple stepwise logistic regression. The final model was obtained by retaining those with $P<0.05$ and some marginally significant clinical variables with $P<0.10$. All tests were two-sided, and $P<0.05$ was considered statistically significant. We used the Hosmer-Lemeshow test to verify the goodness of the model fit. All statistical analyses were evaluated using IBM SPSS Statistics for Windows, Version 23.0 (IBM Corporation, Armonk, NY, USA).

\section{Results}

\section{Clinical characteristics of patients}

The baseline characteristics of the 77 COPD patients are summarized in Table 1. There were 67 males $(87.0 \%)$ and ten females $(13.0 \%)$ with a median age of 73 years (IQR, 66-78 years). The median BMI was $22.3 \mathrm{~kg} / \mathrm{m}^{2}$ (IQR, 20.6$25.2 \mathrm{~kg} / \mathrm{m}^{2}$ ), and 73 patients ( $94.8 \%$ ) were current or former smokers. Of the 77 patients, $61(79.2 \%)$ had at least one comorbidity, the most common of which were hypertension $(n=35,45.5 \%)$, coexisting asthma $(n=25,32.5 \%)$, and malignancy $(\mathrm{n}=17,22.1 \%)$, followed by diabetes mellitus ( $\mathrm{n}=15$, $19.5 \%)$, IHD ( $\mathrm{n}=11,14.3 \%)$, cor pulmonale $(\mathrm{n}=8,10.4 \%)$, and cerebrovascular disease $(n=7,9.1 \%)$. The median arterial blood $\mathrm{pH}$ at the time of the index admission was 7.4 (IQR, 7.4-7.5), and the arterial partial pressure of $\mathrm{CO}_{2}$ was $41 \mathrm{mmHg}$ (IQR, 36-47 mmHg). The median $\mathrm{FEV}_{\mathrm{l}} /$ forced vital capacity was $45 \%$ (IQR, 34\%-55\%) with an $\mathrm{FEV}_{1}$ of $1.1 \mathrm{~L}$ (44\% predicted). Regarding medical treatment, nine patients $(11.7 \%)$ received home oxygen therapy, and nine patients $(11.7 \%)$ were taking long-term oral corticosteroids. Fifty-three patients (68.8\%) used an inhaled corticosteroid/ long-acting $\beta_{2}$-agonist combination, 42 patients (54.5\%) used a long-acting muscarinic antagonist, and 32 patients (41.6\%) used triple therapy including all of the aforementioned medications. Nine patients (11.7\%) did not use any inhalers, because they had mild respiratory symptoms before the index
Table I Baseline characteristics of 77 COPD patients with severe acute exacerbations

\begin{tabular}{|c|c|}
\hline & $\begin{array}{l}\text { Median (IQR, QI-Q3) } \\
\text { or number }(\%)\end{array}$ \\
\hline Age, years & $73(66-78)$ \\
\hline Sex, male & $67(87.0)$ \\
\hline Body mass index, $\mathrm{kg} / \mathrm{m}^{2}$ & $22.3(20.6-25.2)$ \\
\hline \multicolumn{2}{|l|}{ Smoking history } \\
\hline Current or former smoker & $73(94.8)$ \\
\hline Comorbidities & 61 (79.2) \\
\hline Hypertension & $35(45.5)$ \\
\hline Asthma & $25(32.5)$ \\
\hline Malignancy & $17(22.1)$ \\
\hline Diabetes mellitus & $15(19.5)$ \\
\hline Ischemic heart disease & II (14.3) \\
\hline Cor pulmonale & $8(10.4)$ \\
\hline Cerebrovascular disease & $7(9.1)$ \\
\hline Congestive heart failure & $6(7.8)$ \\
\hline Tuberculosis-destroyed lung & $6(7.8)$ \\
\hline Chronic renal disease & $5(6.5)$ \\
\hline Chronic liver disease & $\mathrm{I}(\mathrm{I} .3)$ \\
\hline \multicolumn{2}{|l|}{ Pulmonary function tests } \\
\hline $\mathrm{FEV}_{1} / \mathrm{FVC}, \%$ & $45(34-55)$ \\
\hline $\mathrm{FEV}_{1}, \mathrm{~L}$ & I.I $(0.8-1.5)$ \\
\hline $\mathrm{FEV}_{1}, \%$ predicted & $44(32-57)$ \\
\hline \multicolumn{2}{|l|}{ Laboratory findings } \\
\hline $\mathrm{pH}^{\mathrm{a}}$ in arterial blood & $7.4(7.4-7.5)$ \\
\hline $\mathrm{PaCO}_{2},{ }^{a} \mathrm{mmHg}$ & $4 \mid(36-47)$ \\
\hline $\mathrm{ESR},{ }^{\mathrm{b}} \mathrm{mm} / \mathrm{h}$ & $34(|4-5|)$ \\
\hline $\mathrm{CRP}, \mathrm{mg} / \mathrm{dL}$ & $1.7(0.4-6.2)$ \\
\hline Procalcitonin, ${ }^{c} \mathrm{ng} / \mathrm{mL}$ & $0.1(0.1-0.2)$ \\
\hline \multicolumn{2}{|l|}{ Medical treatments } \\
\hline Home oxygen therapy & $9(11.7)$ \\
\hline Long-term oral steroids & $9(11.7)$ \\
\hline \multicolumn{2}{|l|}{ Inhaler ${ }^{d}$} \\
\hline None & $9(11.7)$ \\
\hline ICS/LABA & $53(68.8)$ \\
\hline LAMA & $42(54.5)$ \\
\hline LABA & $4(5.2)$ \\
\hline Others & $6(7.8)$ \\
\hline
\end{tabular}

Notes: a Data for 69 patients were available. ${ }^{b}$ Data for 56 patients were available. 'Data for 47 patients were available. ${ }^{\mathrm{d}}$ Reported inhaler use prior to first admission; some patients used more than one inhaler.

Abbreviations: CRP, C-reactive protein; ESR, erythrocyte sedimentation rate; $\mathrm{FEV}_{\text {, }}$, forced expiratory volume in I second; FVC, forced vital capacity; ICS, inhaled corticosteroid; IQR, interquartile range; LABA, long-acting $\beta_{2}$-agonist; LAMA, long acting muscarinic antagonist; $\mathrm{PaCO}_{2}$, partial pressure of arterial $\mathrm{CO}_{2}$.

admission for severe AE. According to the Global Initiative for Chronic Obstructive Lung Disease criteria, patients were classified by the severity of airflow limitation as follows: mild $(\mathrm{n}=1,1.3 \%)$, moderate $(\mathrm{n}=28,36.4 \%)$, severe $(\mathrm{n}=33$, $42.8 \%)$, and very severe $(n=15,19.5 \%)$.

\section{Overall treatment outcomes in patients with severe AEs}

Of the 77 patients who had severe AEs, 29 (37.7\%) experienced frequent severe AEs within the 1-year follow-up 
Table 2 Treatment outcomes of 77 COPD patients with severe acute exacerbations

\begin{tabular}{|c|c|c|c|c|c|c|c|}
\hline & \multirow[t]{2}{*}{ Total $(n=77)$} & \multicolumn{3}{|c|}{$\begin{array}{l}\text { Patients with or without early frequent } \\
\text { severe AEs within } 90 \text { days }\end{array}$} & \multicolumn{3}{|c|}{$\begin{array}{l}\text { Patients with or without frequent } \\
\text { severe AEs within I year }\end{array}$} \\
\hline & & $\begin{array}{l}\text { Without } \\
\text { severe AEs } \\
(n=58)\end{array}$ & $\begin{array}{l}\text { With severe } \\
\text { AEs }(n=19)\end{array}$ & $P$-value & $\begin{array}{l}\text { Without } \\
\text { severe AEs } \\
(n=48)\end{array}$ & $\begin{array}{l}\text { With severe } \\
\text { AEs }(n=29)\end{array}$ & $P$-value \\
\hline Hospital stays, days & $5(2-9)$ & $4(2-8)$ & $8(3-11)$ & 0.070 & $4(2-8)$ & $7(3-10)$ & 0.110 \\
\hline $\begin{array}{l}\text { Duration of systemic steroid } \\
\text { treatment during first severe } \\
\text { AE event, days }\end{array}$ & $7(5-10)$ & $7(5-10)$ & $6(5-10)$ & 0.995 & $6(5-9)$ & $7(5-12)$ & 0.308 \\
\hline $\begin{array}{l}\text { Total steroid dose prescribed } \\
\text { between the first day of } A E \\
\text { and OPD visit, } \mathrm{mg}^{\mathrm{a}}\end{array}$ & $238(188-376)$ & $249(188-360)$ & $223(188-400)$ & 1.0 & $239(188-338)$ & $230(188-429)$ & 0.368 \\
\hline $\begin{array}{l}\text { Deaths due to subsequent } \\
\text { severe AEs }\end{array}$ & $5(6.5)$ & $2(3.4)$ & $3(15.8)$ & 0.093 & - & $5(17.2)$ & - \\
\hline
\end{tabular}

Notes: The data are presented as number (\%) or as median and interquartile range. ${ }^{\text {a }}$ Steroid doses were calculated as equivalent doses of prednisolone. Abbreviations: AE, acute exacerbation; OPD, outpatient department.

periods and 19 (24.7\%) had early frequent severe AEs within the 90-day follow-up periods after the index admission. As shown in Table 2, the median hospital stay was 5 days (IQR, 2-9 days). Between the day of admission and the outpatient hospital follow-up visit, systemic steroids were prescribed at a median dose of $238 \mathrm{mg}$ (188-376 mg equivalent dose of prednisolone) for a median of 7 days (IQR, 5-10 days). Overall, a total of five patients $(6.5 \%)$ died due to frequent severe AEs within 1 year of the index severe AE event. There was no significant difference in number of admission days or steroid usage in patients with and without frequent severe $\mathrm{AEs}$, regardless of the timing of the $\mathrm{AE}$ recurrence (ie, within the 90-day or 1-year follow-up period).

\section{Comparison of COPD patients with or without frequent severe AEs during I-year of follow-up}

The clinical characteristics of COPD patients with or without frequent severe AEs are summarized in Table 3. There were no significant differences in age, sex, BMI, smoking history, comorbidities, and laboratory findings in patients with or without frequent severe AEs during the 1-year follow-up period. Compared with patients without frequent severe AEs, patients who experienced frequent severe AEs were more likely to have poor lung function (median $\mathrm{FEV}_{1}[\mathrm{~L}], 1.1 \mathrm{~L}$ vs $1.2 \mathrm{~L}, P=0.049$ ), receive home oxygen therapy ( $24.1 \%$ vs $4.2 \%, P=0.023)$, and long-term oral steroids ( $20.7 \%$ vs $4.2 \%, P=0.047)$.

\section{Comparison of COPD patients with and without early frequent severe AEs during} a 90-day follow-up

Clinical characteristics of COPD patients with or without early frequent severe AEs (within 90 days) are summarized in Table 4. There were no significant differences in age, sex, BMI, smoking history, comorbidities, and laboratory findings between the patients with and without early frequent severe AEs. In contrast to patients without early frequent severe AEs, patients who experienced early frequent severe AEs were more likely to have poor lung function (median $\mathrm{FEV}_{1}[\mathrm{~L}], 0.9 \mathrm{~L}$ vs $1.2 \mathrm{~L}, P=0.008$ ), receive home oxygen therapy ( $26.3 \%$ vs $6.9 \%, P=0.036)$, and long-term oral steroids $(26.3 \%$ vs $5.2 \%, P=0.019)$.

\section{Clinical factors associated with frequent severe AEs within 90 days and I year of follow-up}

As shown in Table 5, multiple logistic regression analysis revealed that patients with asthma were 4.02 times more likely to develop severe AEs ( $95 \%$ confidence interval $[\mathrm{CI}]=1.30-12.46, P=0.016$ ), and those requiring home oxygen therapy were 9.39 times more likely to develop severe AEs ( $95 \% \mathrm{CI}=1.60-55.30, P=0.013$ ). In addition, CRP was significantly associated with development of frequent severe AEs during the 1-year follow-up period (adjusted OR $=1.09,95 \% \mathrm{CI}=1.01-1.19, P=0.036$ ). The $\mathrm{FEV}_{1}$ (adjusted OR $=0.16,95 \% \mathrm{CI}=0.04-0.70, P=0.015$ ) was found to be inversely associated with early frequent severe AEs (Table 5).

\section{Discussion}

The most important finding of the present study was the identification of coexisting asthma as a significant factor in the development of frequent severe AEs in COPD patients within 1 year of the AE episode. Additionally, poor lung function, represented by $\mathrm{FEV}_{1}$, was inversely associated with development of early frequent severe AEs within 90 days 
Table 3 Comparison of 77 COPD patients with or without frequent severe acute exacerbations during a I-year follow-up period

\begin{tabular}{|c|c|c|c|}
\hline & $\begin{array}{l}\text { Patients without frequent } \\
\text { severe AEs }(n=48)\end{array}$ & $\begin{array}{l}\text { Patients with frequent } \\
\text { severe AEs }(n=29)\end{array}$ & $P$-value \\
\hline Age, years & $74(66-79)$ & $71(64-76)$ & 0.377 \\
\hline Sex, male & $42(87.5)$ & $25(86.2)$ & 1.0 \\
\hline Body mass index, $\mathrm{kg} / \mathrm{m}^{2}$ & $22.2(20.5-25.1)$ & $22.4(20.8-25.4)$ & $0.5 \mathrm{II}$ \\
\hline \multicolumn{4}{|l|}{ Smoking history } \\
\hline Current or former smoker & $40(83.3)$ & $24(82.8)$ & 1.0 \\
\hline Comorbidities & $35(72.9)$ & $26(89.7)$ & 0.079 \\
\hline Hypertension & $20(4 I .7)$ & $15(5 \mathrm{I} .7)$ & 0.390 \\
\hline Asthma & $12(25.0)$ & $13(44.8)$ & 0.072 \\
\hline Malignancy & $10(20.8)$ & $7(24.1)$ & 0.735 \\
\hline Diabetes mellitus & $8(16.7)$ & $7(24.1)$ & 0.423 \\
\hline Ischemic heart disease & $7(\mid 4.6)$ & $4(13.8)$ & 1.0 \\
\hline Cor pulmonale & $4(8.3)$ & $4(13.8)$ & 0.466 \\
\hline Cerebrovascular disease & $3(6.2)$ & $4(13.8)$ & 0.415 \\
\hline Congestive heart failure & $3(6.2)$ & $3(10.3)$ & 0.667 \\
\hline Tuberculosis-destroyed lung & $6(12.5)$ & $0(0.0)$ & 0.078 \\
\hline Chronic renal disease & $2(4.2)$ & $3(10.3)$ & 0.359 \\
\hline Chronic liver disease & $\mathrm{I}(2.1)$ & $0(0.0)$ & 1.0 \\
\hline \multicolumn{4}{|l|}{ Pulmonary function tests } \\
\hline $\mathrm{FEV}_{1} / \mathrm{FVC}$ & $45(36-57)$ & $4 \mid(3 I-55)$ & 0.254 \\
\hline $\mathrm{FEV}_{1}, \mathrm{~L}$ & $1.2(0.9-1.6)$ & I.I (0.7-I.3) & 0.049 \\
\hline $\mathrm{FEV}_{1}, \%$ predicted & $44(33-63)$ & $37(27-55)$ & 0.145 \\
\hline \multicolumn{4}{|l|}{ Laboratory findings } \\
\hline $\mathrm{pH}$ in arterial blood ${ }^{\mathrm{a}}$ & $7.4(7.4-7.5)$ & $7.4(7.4-7.5)$ & 0.651 \\
\hline $\mathrm{PaCO}_{2},{ }^{a} \mathrm{mmHg}$ & $43(37-47)$ & $40(35-50)$ & 0.389 \\
\hline $\mathrm{ESR}, \mathrm{b} \mathrm{mm} / \mathrm{h}$ & $32(\mid 4-5 I)$ & $36(22-55)$ & 0.663 \\
\hline $\mathrm{CRP}, \mathrm{mg} / \mathrm{dL}$ & I.I $(0.3-4.9)$ & $3.9(0.5-10.6)$ & 0.064 \\
\hline Procalcitonin, ${ }^{\mathrm{c}} \mathrm{ng} / \mathrm{mL}$ & $0.1(0.1-0.2)$ & $0.2(0.1-0.5)$ & 0.083 \\
\hline \multicolumn{4}{|l|}{ Medical treatments } \\
\hline Home oxygen therapy & $2(4.2)$ & $7(24.1)$ & 0.023 \\
\hline Long-term oral steroids & $2(4.2)$ & $6(20.7)$ & 0.047 \\
\hline Use of ICS after severe $\mathrm{AE}$ & $39(81.3)$ & $28(96.6)$ & 0.080 \\
\hline
\end{tabular}

Notes: The data are presented as number (\%) or as median and interquartile range. ${ }^{\mathrm{D} D a t a}$ for 69 patients were available. ${ }^{\mathrm{b}} \mathrm{Data}$ for 56 patients were available. ${ }^{\mathrm{c}} \mathrm{Data}$ for 47 patients were available.

Abbreviations: AE, acute exacerbation; CRP, C-reactive protein; ESR, erythrocyte sedimentation rate; FEV , forced expiratory volume in I second; FVC, forced vital capacity; ICS, inhaled corticosteroids; $\mathrm{PaCO}_{2}$, partial pressure of arterial $\mathrm{CO}_{2}$.

of the severe AE episode. Patients requiring home oxygen therapy were also more prone to develop frequent severe AEs in the first year after severe AE.

There has been controversy surrounding the roles of comorbidities in the development of frequent severe AEs. ${ }^{22}$ Previous studies have evaluated comorbidities using the Charlson comorbidity index, which has been widely used as a comorbidity-related predictor of AEs in COPD patients. Because this integrated index was used as a single variable,,$^{10,11,14}$ the contribution of each individual comorbidity to frequent severe AEs might be underestimated. In addition, the Charlson comorbidity index does not include asthma, ${ }^{13}$ and past studies excluded COPD patients with asthma when evaluating factors influencing AEs in COPD patients. ${ }^{15,23-28}$ Recently, several studies have highlighted the impact of coexisting asthma in COPD patients. A crosssectional study using previous AE history reported that a history of physician-diagnosed asthma was related to the frequency and severity of exacerbations in COPD patients..$^{29}$ In the PLATINO study using a general population, subjects with coexisting asthma and COPD had a higher risk of exacerbation and hospitalization compared to those patients with COPD alone.$^{30}$ Furthermore, an observational study in a primary care population showed that several comorbidities, including asthma, were associated with moderate-tosevere exacerbations during a 1 -year follow-up period. ${ }^{31}$ We extended these findings by demonstrating a significant association between coexisting asthma and frequent severe COPD AEs in patients cared for in a tertiary hospital setting.

Previously, it was determined that the risk of myocardial infarction increased in the postexacerbation period, and that patients who experienced frequent exacerbations had a higher incidence rate of IHD. ${ }^{32,33}$ Furthermore, Almagro et al ${ }^{10}$ 
Table 4 Comparison of 77 COPD patients with and without early frequent severe acute exacerbations (within 90 days)

\begin{tabular}{|c|c|c|c|}
\hline & $\begin{array}{l}\text { Patients without early frequent } \\
\text { severe AEs }(n=58)\end{array}$ & $\begin{array}{l}\text { Patients with early frequent } \\
\text { severe AEs }(n=19)\end{array}$ & $P$-value \\
\hline Age, years & $74(67-79)$ & $68(63-75)$ & 0.135 \\
\hline Sex, male & $50(86.2)$ & $17(89.5)$ & 1.0 \\
\hline Body mass index, $\mathrm{kg} / \mathrm{m}^{2}$ & $22.3(20.3-25.4)$ & $22.3(21.4-24.8)$ & 0.855 \\
\hline \multicolumn{4}{|l|}{ Smoking history } \\
\hline Current or former smoker & $48(82.8)$ & $16(84.2)$ & 1.0 \\
\hline Comorbidities & $43(74.1)$ & $18(94.7)$ & 0.099 \\
\hline Hypertension & $26(44.8)$ & $9(47.4)$ & 0.847 \\
\hline Asthma & $17(29.3)$ & $8(42.1)$ & 0.301 \\
\hline Malignancy & $12(20.7)$ & $5(26.3)$ & 0.751 \\
\hline Diabetes mellitus & $10(17.2)$ & $5(26.3)$ & 0.505 \\
\hline Ischemic heart disease & $8(13.8)$ & $3(15.8)$ & 1.0 \\
\hline Cor pulmonale & $5(8.6)$ & $3(15.8)$ & 0.400 \\
\hline Cerebrovascular disease & $4(6.9)$ & $3(15.8)$ & 0.354 \\
\hline Congestive heart failure & $3(5.2)$ & $3(15.8)$ & 0.156 \\
\hline Tuberculosis-destroyed lung & $6(10.3)$ & $0(0)$ & 0.327 \\
\hline Chronic renal disease & $4(6.9)$ & $\mathrm{I}(5.3)$ & 1.0 \\
\hline Chronic liver disease & $\mathrm{I}(\mathrm{I} .7)$ & $0(0)$ & 1.0 \\
\hline \multicolumn{4}{|l|}{ Pulmonary function tests } \\
\hline $\mathrm{FEV}_{1} / \mathrm{FVC}$ & $45(35-58)$ & $4 I(30-54)$ & 0.135 \\
\hline $\mathrm{FEV}_{1}, \mathrm{~L}$ & $1.2(0.9-1.6)$ & $0.9(0.6-1.2)$ & 0.008 \\
\hline $\mathrm{FEV}_{1}, \%$ predicted & $46(33-62)$ & $34(20-48)$ & 0.008 \\
\hline \multicolumn{4}{|l|}{ Laboratory findings } \\
\hline $\mathrm{pH}$ in arterial blood ${ }^{\mathrm{a}}$ & $7.4(7.4-7.5)$ & $7.4(7.3-7.5)$ & 0.459 \\
\hline $\mathrm{PaCO}_{2},{ }^{a} \mathrm{mmHg}$ & $4 \mid(36-46)$ & $40(35-67)$ & 0.908 \\
\hline $\mathrm{ESR},{ }^{\mathrm{b}} \mathrm{mm} / \mathrm{h}$ & $30(15-50)$ & $38(20-64)$ & 0.491 \\
\hline CRP, mg/dL & I.I (0.3-5.5) & $5.0(0.4-9.5)$ & 0.124 \\
\hline Procalcitonin, ${ }^{c} \mathrm{ng} / \mathrm{mL}$ & $0.1(0.1-0.2)$ & $0.2(0.1-0.5)$ & 0.146 \\
\hline \multicolumn{4}{|l|}{ Medical treatments } \\
\hline Home oxygen therapy & $4(6.9)$ & $5(26.3)$ & 0.036 \\
\hline Long-term oral steroids & $3(5.2)$ & $5(26.3)$ & 0.019 \\
\hline Use of ICS after severe $\mathrm{AE}$ & $49(84.5)$ & $18(94.7)$ & 0.436 \\
\hline
\end{tabular}

Notes: The data are presented as number (\%) or as median and interquartile range. ${ }^{\mathrm{a} D a t a}$ for 69 patients were available. ${ }^{\mathrm{b}} \mathrm{Data}$ for 56 patients were available. ${ }^{\mathrm{C}} \mathrm{Data}$ for 47 patients were available.

Abbreviations: AE, acute exacerbation; CRP, C-reactive protein; ESR, erythrocyte sedimentation rate; FEV , forced expiratory volume in I second; FVC, forced vital capacity; ICS, inhaled corticosteroid; $\mathrm{PaCO}_{2}$, partial pressure of arterial $\mathrm{CO}_{2}$.

showed that a history of IHD was associated with an increase in crude mortality in 3 months following a severe AE, and a recent study showed that COPD itself is associated with increased risk of myocardial infarction and ischemic stroke. ${ }^{34}$ Nonetheless, the comorbidity of cardiovascular diseases as a whole (IHD, congestive heart failure, and cerebrovascular disease) was not associated with the frequency of severe AEs of COPD in the present study. There are several possible explanations for this lack of association. First, the total number of patients with cardiovascular disease, including IHD and cerebrovascular disease, was relatively small. Thus, further studies with larger study populations are needed to

Table 5 Multiple logistic regression analysis of clinical factors and comorbidities associated with frequent severe acute exacerbations during I-year of follow-up and early frequent severe acute exacerbations during 90 days of follow-up

\begin{tabular}{llcc}
\hline & Adjusted odds ratio & 95\% confidence interval & $P$-value \\
\hline & Factors associated with frequent severe AEs during I-year of follow-up & \\
Asthma & 4.02 & $1.30-12.46$ & 0.016 \\
Home oxygen therapy ${ }^{\mathrm{b}}$ & 9.39 & $1.60-55.30$ & 0.013 \\
CRP & 1.09 & $1.01-1.19$ & 0.036 \\
& Factors associated with early frequent severe AEs during 90 days of follow-up $^{\mathrm{a}}$ & 0.015 \\
FEV, $\mathrm{L}$ & 0.16 & $0.04-0.70$ & 0 \\
\hline
\end{tabular}

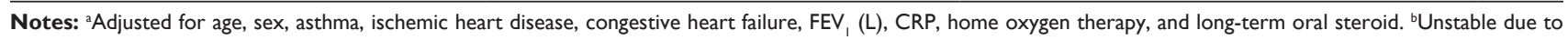
the fact that only two of nine patients who used home oxygen therapy did not develop AE.

Abbreviations: AE, acute exacerbation; CRP, C-reactive protein; $\mathrm{FEV}_{1}$, forced expiratory volume in I second. 
confirm these associations. Second, there is a possibility that the incidence rate of severe AEs following myocardial infarction might be underestimated, since AE events frequently develop during hospitalization for postmyocardial infarction management.

CRP is an inflammatory biomarker that is commonly elevated in COPD patients during exacerbations. ${ }^{35-37} \mathrm{~A}$ large prospective cohort study with 6,574 subjects revealed that stable COPD patients with concurrent elevation in levels of CRP and other inflammatory biomarkers have an increased risk of exacerbations. ${ }^{38}$ Despite these findings, no available data supports an association between elevated CRP level at the time of the index severe AE presentation and the occurrence of subsequent severe AEs. The present study revealed that COPD patients with elevated level of CRP upon presentation with severe exacerbations were more likely to experience subsequent severe exacerbations. However, further studies are needed to validate this correlation in more detail.

Approximately $38 \%$ of subjects in the present study experienced frequent severe AEs after the index admission during the 1-year follow-up period, and about $25 \%$ of subjects experienced frequent severe AEs within 90 days. This observation was concordant with previous studies, which reported a rate of $\sim 35 \%$ to $46 \%$ of frequent severe AEs during 1 year ${ }^{2,5,39}$ and $15 \%$ for frequent severe AEs within 3 months following index events. ${ }^{40}$ Regarding the use of systemic corticosteroids, there was no significant difference in the total dose of systemic corticosteroids used in patients with or without frequent AEs. Consistent with this finding, a previous study reported that a shortterm (5-day) course of systemic corticosteroid therapy was comparable to long-term use, thereby protecting COPD patients with frequent AEs from the harmful effects of excessive exposure to systemic corticosteroids. ${ }^{41}$ Given the frequent severe AEs in a substantial proportion of COPD patients coupled with the increased risk of side effects associated with longer systemic corticosteroid courses, short-term treatment with conventional corticosteroid dosages should be considered, even in COPD patients with frequent severe AEs.

This study has several limitations. First, this retrospective study was performed at a single referral center. Second, the number of patients in this study was relatively small. Thus, the statistical power might not be sufficient to detect associations with other comorbidities. Third, a small number of female COPD patients were included, which is reflective of the low prevalence of female smokers in Korea. ${ }^{42}$
Fourth, because the presence of mental health disorders or the use of psychotropic medications was rarely included in the medical records of our subjects, this study was not able to investigate the contributions of anxiety or depression to COPD-related comorbidity. This might reflect the higher prevalence of mental health disorders found in females than males, compounded by the small number of female COPD patients in the present study. Fifth, due to the exploratory nature of our study, some of the comorbidities are sparsely represented in our data, as reflected in the wide CIs. Sixth, in regard to the exacerbation episodes, it is possible that they were in fact asthma exacerbations in COPD patients with coexisting asthma. This challenge in discriminating between COPD and asthma exacerbations in patients with both diseases has historically led to the exclusion of patients with asthma features from COPD studies and vice versa. However, given that asthma - COPD overlap syndrome is increasingly acknowledged as a phenotype of COPD, the present study included COPD patients with coexisting asthma, despite the possibility of mixed COPD and asthma exacerbations. Finally, because adherence to inhaler therapy was not able to be examined in this study, the effect of poor adherence on frequent severe AEs in COPD patients could not be evaluated.

Nevertheless, our study found a significant and persistent association between coexisting asthma and frequent severe AEs in COPD patients. While more large-scale studies need to be conducted to confirm our conclusions, our findings suggest a need for closer attention to individual comorbidities, especially coexisting asthma, in COPD patients in order to achieve effective prevention and treatment of AEs.

\section{Acknowledgment}

This study was supported by the Samsung Medical Center Foundation for Medical Research (SMO1140211).

\section{Disclosure}

The authors report no conflicts of interest in this work.

\section{References}

1. Global Strategy for the Diagnosis, Management and Prevention of Chronic Obstructive Pulmonary Disease; 2016 [Updated 2016]. Available from: www.goldcopd.org. Accessed April 15, 2016.

2. Donaldson GC, Seemungal TA, Bhowmik A, Wedzicha JA. Relationship between exacerbation frequency and lung function decline in chronic obstructive pulmonary disease. Thorax. 2002;57(10):847-852.

3. Kanner RE, Anthonisen NR, Connett JE. Lower respiratory illnesses promote FEV(1) decline in current smokers but not ex-smokers with mild chronic obstructive pulmonary disease: results from the lung health study. Am J Respir Crit Care Med. 2001;164(3):358-364. 
4. Kessler R, Stahl E, Vogelmeier C, et al. Patient understanding, detection, and experience of COPD exacerbations: an observational, interviewbased study. Chest. 2006;130(1):133-142.

5. Spencer S, Calverley PM, Burge PS, Jones PW. Impact of preventing exacerbations on deterioration of health status in COPD. Eur Respir J. 2004;23(5):698-702.

6. Piquet J, Chavaillon JM, David P, Martin F, Blanchon F, Roche N. High-risk patients following hospitalisation for an acute exacerbation of COPD. Eur Respir J. 2013;42(4):946-955.

7. Singanayagam A, Schembri S, Chalmers JD. Predictors of mortality in hospitalized adults with acute exacerbation of chronic obstructive pulmonary disease. Ann Am Thorac Soc. 2013;10(2):81-89.

8. Gunen H, Hacievliyagil SS, Kosar F, et al. Factors affecting survival of hospitalised patients with COPD. Eur Respir J. 2005;26(2):234-241.

9. Soler-Cataluna JJ, Martinez-Garcia MA, Roman Sanchez P, Salcedo E, Navarro M, Ochando R. Severe acute exacerbations and mortality in patients with chronic obstructive pulmonary disease. Thorax. 2005; 60(11):925-931.

10. Almagro P, Cabrera FJ, Diez J, et al; Working Group on COPD, Spanish Society of Internal Medicine. Comorbidities and short-term prognosis in patients hospitalized for acute exacerbation of COPD: the EPOC en Servicios de medicina interna (ESMI) study. Chest. 2012;142(5): 1126-1133.

11. Almagro P, Salvado M, Garcia-Vidal C, et al. Recent improvement in long-term survival after a COPD hospitalisation. Thorax. 2010;65(4): 298-302.

12. Toy EL, Gallagher KF, Stanley EL, Swensen AR, Duh MS. The economic impact of exacerbations of chronic obstructive pulmonary disease and exacerbation definition: a review. COPD. 2010;7(3):214-228.

13. Charlson ME, Pompei P, Ales KL, MacKenzie CR. A new method of classifying prognostic comorbidity in longitudinal studies: development and validation. J Chronic Dis. 1987;40(5):373-383.

14. Wang Q, Bourbeau J. Outcomes and health-related quality of life following hospitalization for an acute exacerbation of COPD. Respirology. 2005;10(3):334-340.

15. Miravitlles M, Calle M, Alvarez-Gutierrez F, Gobartt E, Lopez F, Martin A. Exacerbations, hospital admissions and impaired health status in chronic obstructive pulmonary disease. Qual Life Res. 2006; 15(3):471-480.

16. Pouw EM, Ten Velde GP, Croonen BH, Kester AD, Schols AM, Wouters EF. Early non-elective readmission for chronic obstructive pulmonary disease is associated with weight loss. Clin Nutr. 2000;19(2): 95-99.

17. Rodriguez-Roisin R. Toward a consensus definition for COPD exacerbations. Chest. 2000;117(5 Suppl 2):398s-401s.

18. Hurst JR, Vestbo J, Anzueto A, et al. Susceptibility to exacerbation in chronic obstructive pulmonary disease. $N$ Engl J Med. 2010;363(12): 1128-1138.

19. Matamis D, Tsagourias M, Papathanasiou A, et al. Targeting occult heart failure in intensive care unit patients with acute chronic obstructive pulmonary disease exacerbation: effect on outcome and quality of life. J Crit Care. 2014;29(2):315.e7-e14.

20. Lee JH, Chang JH. Lung function in patients with chronic airflow obstruction due to tuberculous destroyed lung. Respir Med. 2003; 97(11):1237-1242.

21. Taleb M, Khuder S, Tinkel J, Khouri SJ. The diagnostic accuracy of Doppler echocardiography in assessment of pulmonary artery systolic pressure: a meta-analysis. Echocardiography. 2013;30(3):258-265.

22. Bahadori K, FitzGerald JM. Risk factors of hospitalization and readmission of patients with COPD exacerbation - systematic review. Int J Chron Obstruct Pulmon Dis. 2007;2(3):241-251.

23. Jenkins CR, Jones PW, Calverley PM, et al. Efficacy of salmeterol/ fluticasone propionate by GOLD stage of chronic obstructive pulmonary disease: analysis from the randomised, placebo-controlled TORCH study. Respir Res. 2009;10:59.
24. Beeh KM, Glaab T, Stowasser S, et al. Characterisation of exacerbation risk and exacerbator phenotypes in the POET-COPD trial. Respir Res. 2013;14:116.

25. Lau AC, Yam LY, Poon E. Hospital re-admission in patients with acute exacerbation of chronic obstructive pulmonary disease. Respir Med. 2001;95(11):876-884.

26. Gadoury MA, Schwartzman K, Rouleau M, et al. Self-management reduces both short- and long-term hospitalisation in COPD. Eur Respir J. 2005;26(5):853-857.

27. Miravitlles M, Guerrero T, Mayordomo C, Sanchez-Agudo L, Nicolau F, Segu JL. Factors associated with increased risk of exacerbation and hospital admission in a cohort of ambulatory COPD patients: a multiple logistic regression analysis. The EOLO Study Group. Respiration. 2000;67(5):495-501.

28. Tashkin DP, Celli B, Senn S, et al; UPLIFT Study Investigators. A 4-year trial of tiotropium in chronic obstructive pulmonary disease. N Engl J Med. 2008;359(15):1543-1554.

29. Hardin M, Silverman EK, Barr RG, et al. The clinical features of the overlap between COPD and asthma. Respir Res. 2011;12:127.

30. Menezes AM, Montes de Oca M, Perez-Padilla R, et al. Increased risk of exacerbation and hospitalization in subjects with an overlap phenotype: COPD-asthma. Chest. 2014;145(2):297-304.

31. Mullerova H, Shukla A, Hawkins A, Quint J. Risk factors for acute exacerbations of COPD in a primary care population: a retrospective observational cohort study. BMJ Open. 2014;4(12):e006171.

32. Donaldson GC, Hurst JR, Smith CJ, Hubbard RB, Wedzicha JA. Increased risk of myocardial infarction and stroke following exacerbation of COPD. Chest. 2010;137(5):1091-1097.

33. Campo G, Pavasini R, Malagu M, et al. Chronic obstructive pulmonary disease and ischemic heart disease comorbidity: overview of mechanisms and clinical management. Cardiovasc Drugs Ther. 2015;29(2): 147-157.

34. Yin L, Lensmar C, Ingelsson E, Back M. Differential association of chronic obstructive pulmonary disease with myocardial infarction and ischemic stroke in a nation-wide cohort. Int J Cardiol. 2014;173(3): 601-603.

35. Karadeniz G, Polat G, Senol G, Buyuksirin M. C-reactive protein measurements as a marker of the severity of chronic obstructive pulmonary disease exacerbations. Inflammation. 2013;36(4):948-953.

36. Clark TW, Medina MJ, Batham S, Curran MD, Parmar S, Nicholson KG. C-reactive protein level and microbial aetiology in patients hospitalised with acute exacerbation of COPD. Eur Respir J. 2015;45(1):76-86.

37. Stolz D, Christ-Crain M, Morgenthaler NG, et al. Copeptin, C-reactive protein, and procalcitonin as prognostic biomarkers in acute exacerbation of COPD. Chest. 2007;131(4):1058-1067.

38. Thomsen M, Ingebrigtsen TS, Marott JL, et al. Inflammatory biomarkers and exacerbations in chronic obstructive pulmonary disease. JAMA. 2013;309(22):2353-2361.

39. Cao Z, Ong KC, Eng P, Tan WC, Ng TP. Frequent hospital readmissions for acute exacerbation of COPD and their associated factors. Respirology. 2006;11(2):188-195.

40. Gonzalez C, Servera E, Ferris G, Blasco ML, Marin J. Factores predictivos de reingreso hospitalario en la agudización de la EPOC moderada-grave [Risk factors of readmission in acute exacerbation of moderate-to-severe chronic obstructive pulmonary disease]. Arch Bronconeumol. 2004;40(11):502-507.

41. Leuppi JD, Schuetz P, Bingisser R, et al. Short-term vs conventional glucocorticoid therapy in acute exacerbations of chronic obstructive pulmonary disease: the REDUCE randomized clinical trial. JAMA. 2013;309(21):2223-2231.

42. Ministry of Health and Welfare Republic of Korea. OECD Health Data 2013. Sejong: Ministry of Health and Welfare; 2013. 
International Journal of COPD

\section{Publish your work in this journal}

The International Journal of COPD is an international, peer-reviewed journal of therapeutics and pharmacology focusing on concise rapid reporting of clinical studies and reviews in COPD. Special focus is given to the pathophysiological processes underlying the disease, intervention programs, patient focused education, and self management protocols.

This journal is indexed on PubMed Central, MedLine and CAS. The manuscript management system is completely online and includes a very quick and fair peer-review system, which is all easy to use. Visit http://www.dovepress.com/testimonials.php to read real quotes from published authors 